\title{
Intussuscepted caecal cancer in a patient with intestinal malrotation and
}

\section{agenesis of one kidney}

\author{
Jamry Andrzej
}

Surgical Department Regional Hospital, Starachowice, 27-200 Poland

\section{CASE STUDY}

Please cite this paper as: Jamry A. Intussuscepted caecal cancer in a patient with intestinal malrotation and agenesis of one kidney. AMJ 2018;11(10):497-501. https://doi.org/10.21767/AMJ.2017.3287

\section{Corresponding Author:}

Jamry Andrzej

Surgical Department Regional Hospital,

Starachowice 27-200 Poland

Email: jamry@tlen.pl

\section{ABSTRACT}

We present the case of 60-year-old man (twin) with ileus cause by intussusception of the caecum adenocarcinoma and coexistence of intestinal malrotation (IM) and agenesis of one kidney. Intestinal malrotation with colon carcinoma is very rare in adult patients (only 14 cases have been described in the literature). lleus cause by tumour intussusception has been previously reported in only one patient and the additional coexistence of agenesis of one kidney has not been reported in the available medical literature. However, coexistence of other anomalies was observed in 46 per cent of patients with IM. Therefore, in patients with ileus and coexisting congenital anomalies in other organs, the existence of intestinal malrotation should be considered. Furthermore, because of the unusual anatomy of the mesenteric vessels, right colon resection in patients with IM should be performed with special caution and the preoperative work-up should be extended to include visceral angiography.

\section{Key Words}

Intussusception, congenital defects, colon cancer

\section{Implications for Practice:}

\section{What is known about this subject?}

Intestinal malformations with colon carcinoma have been described in only 14 cases. 46 per cent of patients with IM have other congenital malformations.

\section{What new information is offered in this case study?}

Caecal carcinoma intussusception with intestinal malrotation and the additional coexistence of agenesis of one kidney has not been reported in the available literature.

3. What are the implications for research, policy, or practice?

In patients with abdominal pain, signs of ileus and congenital malformations in other organs, the presence of intestinal malrotation should be considered.

\section{Background}

Intestinal malrotation (IM) is a congenital malformation that may be isolated or coexist with other malformations. IM leads to abnormal intestinal fixation, characterized by a mesenterium ileocolicum commune which supply terminal ileum, caecum, ascending and right half of the transverse colon. These anatomical abnormalities most often lead to twisting of the intestine with subsequent ischemia. Symptoms of IM occur in 1 in 500-600 healthy births. ${ }^{1,2}$ In 50-90 per cent of patients, the disorder is diagnosed within the first year of life. Symptoms leading to diagnosis and surgery in adulthood are rare, and in most cases, IM is not identified during preoperative work-up. ${ }^{3-5} \mathrm{~A}$ barium enema study of 2,000 adults demonstrated that the prevalence of IM was 0.2 per cent. ${ }^{6}$ Only 14 cases of I.M with coexistence of colon carcinoma (CRC) have been reported in the available literature, and ileus cause by intussusception in only one. ${ }^{7}$ Additionally, the presence of $\mathrm{IM}$ in twins has been described in only two cases. ${ }^{8,9}$ To our knowledge, there are currently no published reports of IM coexisting with caecal tumour invaginated to the transverse colon and agenesis of one kidney in adult twins. 


\section{Case details}

A 60-year-old man (twin) was admitted to the surgical department complaining of abdominal pain in in the right lower quadrant with abdominal tension and subileus symptoms. For several months prior to admission, the patient felt pain in the abdomen that was not intense enough to introduce any diagnostic procedures. During the preoperative work-up, abdominal X-ray showed subileus (Figure 1) and CT scan identified colon intussusception located on the upper part of the belly with suspicion of colon cancer, but IM was not identified (Figure 2). Simultaneously, right kidney agenesis and $3 \mathrm{~cm}$ diameter tumour in the upper pole of the left kidney were identified. During colonoscopy, intubations were stopped at about $40 \mathrm{~cm}$ due to severe pain. Laboratory tests: WBC $7.6 \times 10^{\wedge} 3 \mathrm{Ml} ; \mathrm{Hgb} 15.6 \mathrm{~g} / \mathrm{dl} ;$ Hct 42.3 per cent PLT $277 \times 10^{\wedge} 3 \mathrm{Ml} ;$ ALAT12U/L Aspat $14 \mathrm{U} / \mathrm{L}$ Creatynine $0.92 \mathrm{mg} / \mathrm{dl}$ INR $1.04 \mathrm{Na} 138 \mathrm{mmol} / \mathrm{I} \mathrm{K} 4.5 \mathrm{mmol} / \mathrm{I}$ CRP $133.5-33.7 \mathrm{mg} / \mathrm{l}$ CEA $6.03 \mathrm{ng} / \mathrm{ml}$. During laparotomy, intussusception of the caecal tumour (adenocarcinoma T3, NO, MO) to the transverse colon with micro perforation of the colonic wall was confirmed. Simultaneously, non-rotation of the duodenum and ascending colon was identified (Figure 3 intraoperative picture). Right extended hemicolectomy with ileo-transvero anastomosis was performed. The extent of colon resection was determined by the length of intussusception and place of perforation in the transverse colon. The patient remained in stable general condition after the surgery and was discharged to ambulatory treatment in the ninth postoperative day with. In diagnostics performed in an outpatient mode, the benign nature of kidney tumour was established and qualified only for further follow-up.

\section{Discussion}

Only 14 reports of patients with coexisting colon cancer (CRC) and intestinal malrotation have been presented in the literature however, only one of them had intussusception, as in the patient described in our study. ${ }^{10}$ Additionally, Imamura ${ }^{11}$ described the case of a patient with IM coexisting with rectal and stomach cancers. Furthermore, we found no reports of coexistence of IM with kidney agenesis. To our knowledge, this is the first report of a patient presenting with all three of these abnormalities (IM, CC and kidney agenesis). In most patients with IM, the diagnosis is established in the first year of life, and diagnosis of this anomaly in adults is rare. Therefore so, proper preoperative diagnosis of IM in adults is rare. ${ }^{3}$ This is due to the fact that just like in the described case, the preoperative abdominal X-ray was most often shown only subileus. However, a CT scan performed in emergency mode with co- occurring gastrointestinal obstruction is usually an indication for surgical treatment. Therefore, in view of the rarity of IM in the entire population, the radiologist is not focused on seeking this anomaly. In addition, in the presented case, the co-occurrence of the intussusception was additionally difficult by the correct interpretations.

Embryological defect responsible for the development of I.M. occur during the tenth to twelfth gestational week, when the intestine begins to turn 270 degrees' counterclockwise around the axis of the superior mesenteric artery and attaches to the posterior abdominal wall. ${ }^{12}$ According to the arrest point of development intestinal malrotation has been divided into four types: nonrotation (53.3 per cent), malrotation (31.1 per cent), reversed rotation (6.7 per cent), and paraduodenal hernia (8.9 per cent). Seventy-five per cent of individuals with both CC and IM present with the non-rotational type. ${ }^{10,12-15}$ In addition, patients with IM also often present with common mesentery of the ileum, cecum, ascending colon, and the right half of the transverse colon. Therefore, it is possible that the shape of the mesentery promotes the formation of long intussusception, as occurred in the presented case, even though colon intussusceptions has been reported in only one of the fourteen patients with IM and CC.

It remains unclear whether the presence of IM increases the incidence of CRC. Interestingly, 75-82 per cent of colon cancers in patients with IM are in the right colon. ${ }^{10,16}$ Therefore, Ren and $\mathrm{Lu}^{17}$ suggest that improper fixation of this part of the Gl tract generates chronic subileus which can provoke can cause chronic inflammation and the development of colon cancer.

Other anomalies have been reported in 46 per cent of patients with IM. Several patterns of vascular and visceral abnormalities are associated with heterotaxia, and two syndromes of splenic anomalies (asplenia and polysplenia) are most common. ${ }^{18}$ In addition, intestinal atresia, inperforate anus, duodenal web, heart disease (dextrocardia, congenital heart disease) and orthopaedic anomalies ${ }^{11,19-22}$ have been observed in patients with IM. However, the coexistence of CRC, IM and single kidney agenesis has not been previously reported in the available literature. Because of this in patients with the presence of the above-mentioned malformations which appears a mechanical ileus the existence of IM should be considered.

Surgical treatment of I.M. with symptoms of obstruction is performed using open or laparoscopic separate Ladd's band and by widening the root of the mesentery between the 
duodenum and the ascending colon, with a full unveiling of superior mesenteric artery (SMA), and performing a preventive appendectomy (the LADD procedure). ${ }^{15,20,23-25}$ In addition, some centres recommend the execution of duodeno or coecopexy. ${ }^{26,27}$ Operations in asymptomatic patients with IM, especially outside the neonatal period, are the subject of controversy. ${ }^{20}$ This is a consequence of the potential complications, since 26 per cent of patients require re-hospitalization in the post-operative period, 24 per cent subsequently present symptoms of $\mathrm{Gl}$ tract obstruction, 13 per cent require numerous subsequent hospitalizations, 13 per cent require an additional operation and 9 per cent of patients have problems with nutrition. ${ }^{28}$ In adults, the risk of complications is even higher because the re-operations are required in almost 40 per cent patients and serious complication affects 50-60 per cent of them. ${ }^{28,29}$

Of course, in the presented case, the implemented surgical procedure resulted from the co-occurrence of intestinal cancer with intussusception. However, it should be noted that patients with IM have unusual anatomy of the mesenteric vessels. Therefore, the way the spread of cancer can differ from the standard. Therefore, to safely perform adequate extent of resection and lymphadenectomy, preoperative angio CT should be performed. In addition, some authors recommend subserosal peritumoral injection of patent blue violet to detect the correct direction of lymphatic drainage. ${ }^{30}$ In the present case, the operation was done in emergency manner, therefore IM diagnosed was done during laparotomy. Therefore, the exact anatomy of the mesenteric vessels was not known. Although the extent of resection and lymphadenectomy resulted in the field of intussusception and micro-perforations of transverse colon. Therefore, the extent of resection was to more extensive than the one recommended in the case of the cecum cancer.

\section{Conclusion}

Intestinal malrotation is a defect rarely diagnosed in adults, which can promote the development of cancer of the cecum. It is characterized by among other unusual anatomy of the mesenteric vascular malformations and other organs occur in 46 per cent of patients. Therefore, in the case of operations due to CRC in patients with malformations of other organs should be no account of the possibility of unusual mesenteric vascular anatomy.

\section{Learning points}

In patients with abdominal pain with characteristics of subileus and malformations in other organs the presence of intestinal malrotation should be considered because of the unusual anatomy of the mesenteric vessels in patients with intestinal malrotation and cancer of the cecum adequate bowel resection requires preoperative visceral angiography.

\section{References}

1. Pierro A, Ong EG. Malrotation. In: Puri P, Hollwart ME, editors. Pediatric Surgery. New York: Springer-Verge Berlin Heidelberg; 2004. p. 197-201.

2. Torres AM, Ziegler MM. Malrotation of the intestine. World J Surgery. 1993;17(3):326-331.

3. Durkin ET, Lund DP, Shaaban AF, et al. Age-related differences in diagnosis and morbidity of intestinal malrotation. J Am Coll Surg. 2008;206:658-663.

4. Stauffer UG, Herrmann P. Comparison of late results in patients with corrected intestinal malrotation with and without fixation of the mesentery. J Pediatr Surg. 1980;15:9-12.

5. Hajivassiliou CA. Intestinal obstruction in neonatal/pediatric surgery. Semin Pediatr Surg. 2003;12:241-253.

6. Kantor JL. Anomalies of the colon. Radiology. 1934;23(6):651-662.

7. Lu IL. Adenosquamous carcinoma of the cecum with malrotation and intussusceptions. J Can Res Pract. 2014;30(1):70-74.

8. Crowley JJ, Bawle E. Small bowel malrotation in each of a pair of identical twins. Pediatr Radiol. 1996;26(2):127128.

9. Smith SD. Disorders of intestinal rotation and fixation. Pediatric Surgery. In: Grosfeld JL, O'Neill JR, editors. New York: Elsevier; 2006. p. 1346.

10. Nakiyama Y, Akiyama M, Sawatsubashi Y, et al. A case of advanced descending colon cancer in an adult patient with intestinal malrotation. Case Rep Gastrointest Med. 2016;2016:3194056. http://dx.doi.org/10.1155/2016/3194056

11. Iwamura T, Shibata $N$, Haraguchi $Y$, et al. Synchronous double cancer of the stomach and rectum with situs inversus totalis and polysplenia syndrome. J Clin Gastroenterol. 2001;33(2):148-153.

12. Strouse PJ. Disorders of intestinal rotation and fixation ("malrotation"). Pediatr Radiol. 2004;34(11):837-851.

13. Wang CA, Welch CE. Anomalies of intestinal rotation in adolescents and adult. Surgery. 1963;54:839-855.

14. Kato K, Sakurai H, Matsuda S, et al. A case of acute appendicitis presenting with left lower abdominal pain associated with malrotation of the intestine. The Journal of the Japanese Practical Surgeon Society. 1996;57(10):2494-2498.

15. Mazziotti MV, Strasberg SM, Langer JC. Intestinal 
rotation abnormalities without volvulus: The role of laparoscopy. J Am Coll Surg. 1997;185:172-176.

16. Maeda C, Hidaka E, Uchida T, et al. A case of transverse colon cancer with adult intestinal malrotation. Journal of Japan Surgical Association. 2013;74(11):3103-3107.

17. Ren PT, Lu BC. Intestinal malrotation associated with colon cancer in an adult: report of a case. Surg Today. 2009;39(7):624-7. doi: 10.1007/s00595-008-3913-5. Epub 2009 Jun 28.

18. Muneta S, Sakaj S, Fukuda H, et al. Polypsplenia syndrome with various visceral anomalies in adults. Embryological and clinical considerations. Intern Med. 1992;31(8):1026-1031.

19. Powell DM, Othersen HB, Smith CD. Malrotation of the intestines in children: the effect of age on presentation and therapy. J Pediatr Surg. 1989;24:777-780.

20. Lessin MS, Luks FI. Laparoscopic appendectomy and duodenocolonic dissociation (LADD) procedure for malrotation. Pediatr Surg Int. 1998;13:184-185.

21. Sharland MR, Chowcat NL, Qureshi SA, et al. Intestinal obstruction caused by malrotation of the gut in atrial isomerism. Arch Dis Child. 1989;65:1623-1626.

22. Seashore JH, Touloukian RJ. Midgut volvulus, an ever present threat. Arch Pediatr Adolesc Med. 1994;148:4346.

23. Fraser JD, Aguayo P, Sharp SW, et al. The role of laparoscopy in the management of malrotation. J Surg Res. 1009;156:80-82.

24. Kalfa N, Zamfir C, Lopez M, et al. Conditions required for laparoscopic repair of subacute volvulus of the midgut in neonates with intestinal malrotation. Five cases. Surg Endosc. 2004;18:1815-1817.

25. Hagendoorn J, Vieira-Travassos D, van der Zee D. Laparoscopic treatment of intestinal malrotation in neonates and infants: retrospective study. Surg Endosc. 2011;25:217-220.

26. Houben JJ, Ickx B, Closset J, et al. Presented at the III Annual Conference of the Groupement d'Etude de Coeliochirurgie Infantile, 12 June, 1993.

27. Yamashita $\mathrm{H}$, Kato $\mathrm{H}$, Uyama $\mathrm{S}$, et al. Laparoscopic repair of intestinal malrotation complicated by midgut volvulus. Surg Endosc. 1999;13:1160-1162.

28. Murphy FL, Sparnon AL. Long-term complications following intestinal malrotation and the Ladd's procedure: a 15 year review. Pediatr Surg Int. 2006;22:326-329.

29. Draus JM Jr, Foley DS, Bond SJ. Laparoscopic Ladd procedure: a minimally invasive approach to malrotation without midgut volvulus. Am Surg. 2007;73:693-696.

30. Brillantino A, Marano L, Schettino M, et al. Report of a rare case of colon cancer complicated by anomalies of intestinal rotation and fixation: a case report. Cases J. 2009;2:6555.

\section{PEER REVIEW}

Not commissioned. Externally peer reviewed.

\section{CONFLICTS OF INTEREST}

The authors declare that they have no competing interests.

\section{FUNDING}

None

\section{PATIENT CONSENT}

The authors, Jamry A J, declare that:
1. They have obtained written, informed consent for the publication of the details relating to the patient(s) in this report.
2. All possible steps have been taken to safeguard the identity of the patient(s).
3. This submission is compliant with the requirements of local research ethics committees.


Figure 1 - Abdominal X-ray

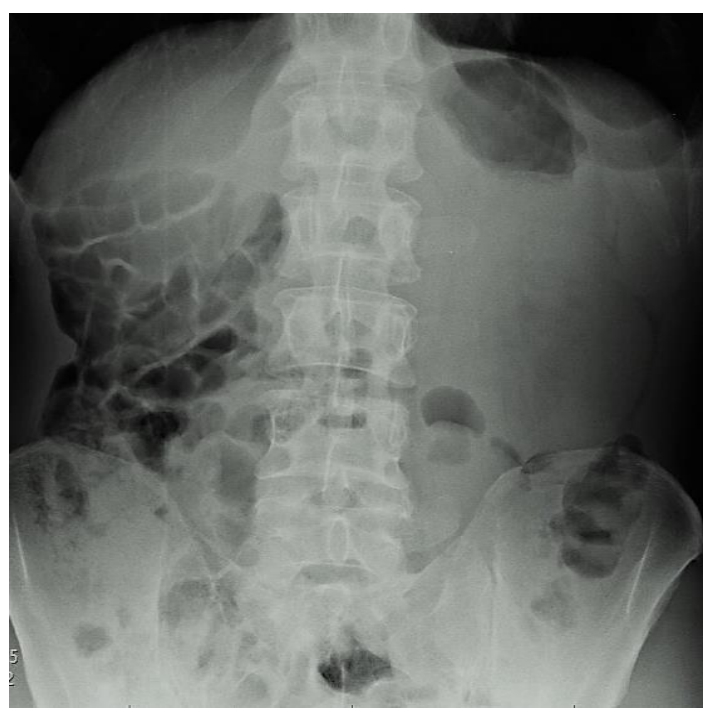

Figure 2: CT scan

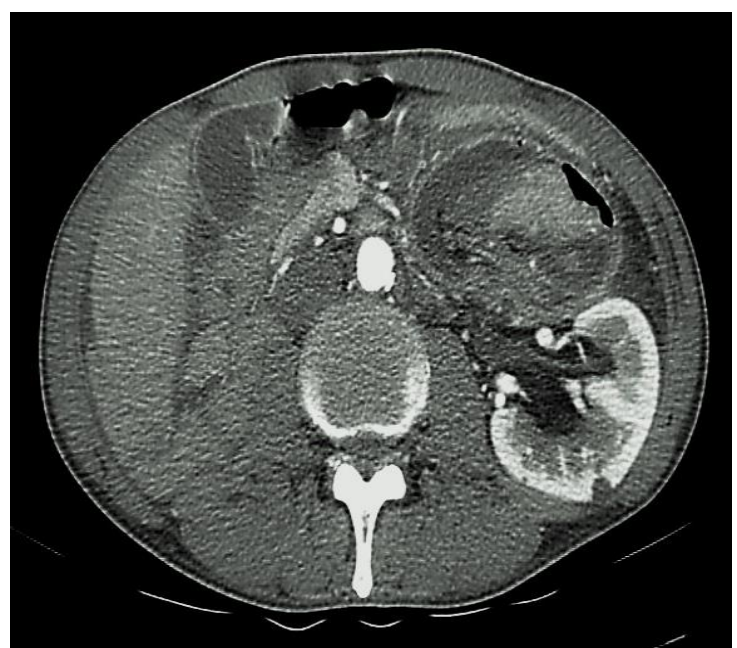

Figure 3: Intraoperative image

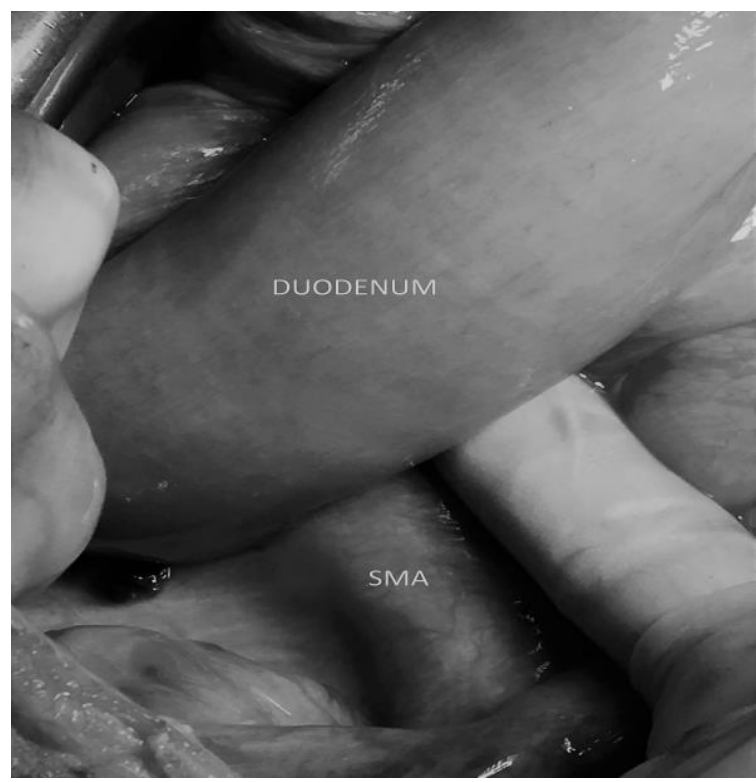

